NASA Technical Memorandum 106997

\title{
A Numerical Model for Dynamic Wave Rotor Analysis
}

D.E. Paxson

Lewis Research Center

Cleveland, Ohio

Prepared for the 31st Joint Propulsion Conference and Exhibit cosponsored by AIAA, ASME, SAE, and ASEE San Diego, California, July 10-12, 1995

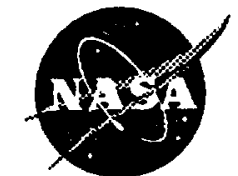



A NUMERICAL MODEL FOR

DYNAMIC WAVE ROTOR ANALYSIS

\author{
D. E. Paxson" \\ NASA Lewis Research Center \\ 21000 Brookpark Rd., Cleveland, Ohio 44135 \\ Mail Stop 77-1
}

(216) 433-8334

\begin{abstract}
A numerical model has been developed which can predict the dynamic (and steady state) performance of a wave rotor, given the geometry and time dependent boundary conditions. The one-dimensional, perfect gas, CFD based code tracks the gas dynamics in each of the wave rotor passages as they rotate past the various ducts. The model can operate both on and off-design, allowing dynamic behavior to be studied throughout the operating range of the wave rotor. The model accounts for several major loss mechanisms including finite passage opening time, fluid friction, heat transfer to and from the passage walls, and leakage to and from the passage ends. In addition it can calculate the amount of work transferred to or from the fluid when the flow in the ducts is not aligned with the passages such as occurs in off-design operation. Since it is one- dimensional, the model runs reasonably fast on a typical workstation. This paper will describe the model and present the results of some transient calculations for a conceptual four port wave rotor designed as a topping cycle for a small gas turbine engine.
\end{abstract}

\section{Introduction}

The wave rotor is being investigated for use as a core gas generator in future multi-spool gas turbine engines in order to achieve high peak cycle temperatures and pressures with conventional materials technology. The device, shown schematically in Fig. 1 uses gasdynamic waves to transfer energy directly to and from the working fluid through which the waves travel. Many descriptions of wave rotor operating principles exist in the literature (see Ref. 1 for a list), and one will not be provided here.

The wave rotor is inherently an unsteady device in that gasdynamic waves are continually traversing the passages as they rotate within the casing. However, aside from the periodic fluctuations arising from the opening and closing of the passages as they enter and exit port regions, the flows in the ports are steady as long as the external boundary conditions are constant in time. This condition shall be referred to as steady state operation. Referring to Fig. 1, the external boundaries would include the combustor fuel flow, the upstream compressor discharge state, the downstream turbine inlet state, and the rotor speed.

\footnotetext{
Member AIAA
}

Copyright 01995 by the American Institute of Aeronautics and Astronautics, Inc. No copyright is asserted in the United States under Title 17, U.S. Code. The U.S. Government has royalty-free license to exercise all rights under the copyright claimed herein for Governmental purposes. All other rights are reserved by the copyright owner.

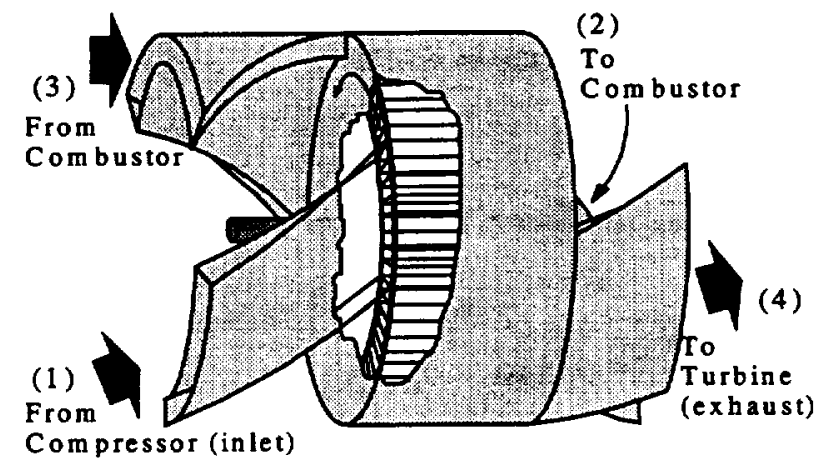

Figure 1 Schematic of a four port wave rotor

Although the steady-state performance of the wave rotor appears promising for topping conventional gas turbine engines, ${ }^{2-4}$ critical questions concerning transient and dynamic performance remain. For example, how does the wave rotor respond to fuel flow changes? Does a wave rotor exhibit instabilities such as surge? How does transient behavior compare with that of conventional turbomachinery? To answer these and other questions, a numerical model has been developed which predicts the dynamic state of the fluid in all of the passages of the wave rotor as they are exposed to time dependent conditions in the various ports. The passages are assumed to have uniform properties at any cross section (i.e. one dimensional flow), and the gas is assumed calorically and thermally perfect. Besides predicting the unsteady gas dynamics which govern the wave rotor operation, the model is capable of assessing losses induced by viscosity, heat transfer to and from the passage walls, the finite opening time of the passages as they enter and exit port regions, non-uniformities in the port flows, and gas leakage between the passage ends and the stationary walls to and from the cavity in the center of the rotor. ${ }^{47}$ It is also capable of calculating the off-design work transfer which occurs when the flow in the ducts is not aligned with the rotor passages (i.e. flow turning). Since all of the passages are tracked simultaneously it is also possible to calculate the instantaneous torque on the drive shaft (and the acceleration of the rotor shaft if no drive motor is present). The combustor, the cavity in the center of the wave rotor, and the rotor wall metal have much longer response times than the gasdynamic waves in the rotor passages and have thus been modeled using lumped volume techniques. To the authors' knowledge, this model represents the first transient wave rotor simulation in the literature. 
This paper will describe the model. Results from several example simulations will be then presented and discussed, followed by some closing remarks.

\section{Model Description}

Much of the passage gasdynamic modeling has been described in other references. ${ }^{1,5}$ In these papers only a single passage of the wave rotor was followed as it rotated about the circumference; however, the approach to the internal flow is exactly the same in the present multipassage model. As such, equations will be repeated here for reference, but will not be discussed.

\section{Governing Equations}

The governing equations in the passages are assumed to be of the form

$$
\frac{\partial x}{\partial t}+\frac{\partial E(w)}{\partial x}=S(w)
$$

where

$$
\ddot{H}=\left[\begin{array}{l}
\rho \\
\left.\frac{p}{\gamma(\gamma-1)}+\frac{\rho u^{2}}{2}\right)
\end{array}\right]
$$

and

$$
E=\left[\begin{array}{l}
p u \\
\frac{p}{\gamma}+p u^{2} \\
u\left(\frac{p}{(\gamma-1)}+\frac{p u^{2}}{2}\right)
\end{array}\right]
$$

These equations have been non-dimensionalized using a reference state $p^{*}, p^{*}$, and $a^{*}$, where $a^{*}$ is the speed of sound, and the ratio of specific heats, $\gamma$. In this form the perfect gas law may be written as $p=p T$. The distance has been scaled by the passage length, $L$, and the time has been scaled using the wave transit time, $\frac{L}{a *}$. For all of the results to be presented, the reference state is the wave rotor inlet stagnation state (port 1 in Fig. 1). The source vector $\mathbf{S}(w)$ accounts for viscous effects (i.e. friction), heat transfer from the passage walls to the gas, and leakage from the passages to the hollow center cavity of the rotor and to the ports. Leakage is assumed to occur only at the ends of any passage. Thus, for the intermediate region where there is no leakage the source vector may be written as

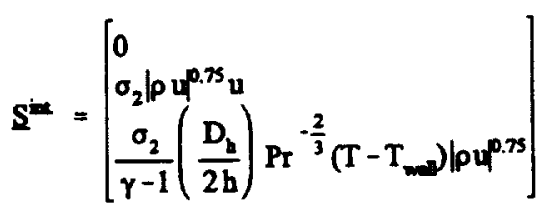

where $D_{b}$ is the passage hydraulic diameter, $h$ is the passage height, $P r$ is the Prandtl number, $T$ is the gas static temperature, and $T_{w \text { wl }}$ is the passage wall temperature. The term $\sigma_{2}$ is a semi-emperically derived constant ${ }^{7}$ based on the passage geometry and reference conditions:

$$
\sigma_{2}=-5.448\left(\frac{L}{D_{h}}\right)^{1.001}\left(\frac{p^{*} \mathrm{a}^{*} \mathrm{~L}}{\mu}\right)^{-0.3953}
$$

The dynamic viscosity is assumed constant. The third term of the source vector in Eqn. 4 is derived from the Reynolds-Colburn heat transfer, skin friction analogy ${ }^{8}$ with heat transfer assumed to occur only from the upper and lower surfaces of the passage and not from the sides.

For the ends of the passage where leakage occurs, the source vector is written as

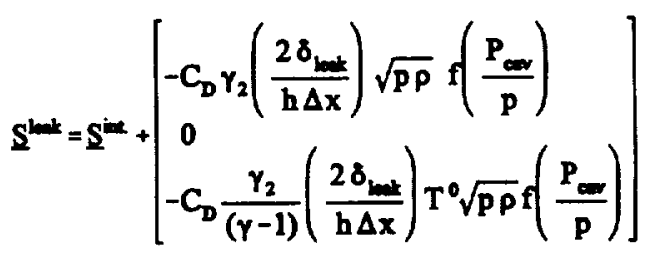

where the function $\mathrm{f}\left(\frac{\mathbf{P}_{\mathrm{cm}}}{\mathbf{p}}\right)$ is the well known St. Venant's orifice equation', $\mathrm{p}_{\mathrm{cav}}$ is the pressure of the gas in the rotor center cavity, $\delta_{\text {leat }}$ is the gap between the rotor and casing endwall, $\Delta \mathrm{x}$ is the non-dimensional grid spacing used in the computational scheme to be described below (it is assumed that the leakage gap is much smaller than the grid spacing), $\quad \gamma_{2}=\sqrt{\frac{2}{\gamma-1}}, T^{0}$ is the gas stagnation temperature, and $C_{D}$ is the seal discharge coefficient, assumed here to be 0.8 . If the cavity pressure is greater than cell pressure then the pressure ratio in Eqn. 6 is inverted, the sign changes, and $p, \rho, T^{0}$ become those of the rotor center cavity.

Eqn. 1 is integrated numerically using the following LaxWendroff technique described in Ref. 1:

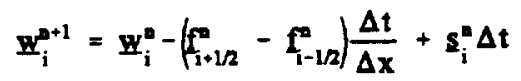

where the numerical flux estimate $\mathfrak{f}_{\mathrm{i}+1 / 2}$ is

$$
\mathrm{f}_{1+1 / 2}^{n}=\frac{\mathrm{E}_{i+1}^{n}+E_{i}^{n}}{2}-\frac{\Phi_{1+1 / 2}^{100}}{2}+\frac{\Delta t}{4}\left([A]_{i+1}^{0} S_{i+1}^{n}+[A]_{i}^{n} S_{i}^{n}\right)
$$

and the numerical source $\mathbf{s}_{i}^{\mathrm{n}}$ is

$$
\mathbf{s}_{i}^{n}=\frac{1}{2}\left(3 \mathbf{S}_{i}^{n}-\mathbf{s}_{i}^{n-1}\right)
$$

The term $\Phi^{\text {Roe }}$ in Eqn. 8 refers to the flux limited dissipation based on Roe's ${ }^{10}$ approximate Riemann solver for equation 1 without a source vector. The matrix [A] is the Jacobian of the flux vector $E$. The superscript $n$ 
indicates the discrete temporal index $n \Delta t$, and the subscript $i$ indicates the spatial index $i \Delta x$. Unless otherwise stated all results to be presented in this report used a ratio of $\Delta t \Delta x=0.3$, with $\Delta x=0.02$. The leakage source term, Eqn. 6 , is applied to the first and last cell in the computing domain.

\section{Passage Wall Temperature}

The wall temperature for each computational cell of each passage is updated using simple Euler integration on a lumped capacitance model of the wall section via

$$
\begin{aligned}
& T_{m_{i}}^{n+1}=T_{m_{i}}^{n}+\left[-\phi_{1}\left(s_{3}^{m}\right)_{i}^{n}+\phi_{2}\left(T_{c o n}^{n}-T_{n_{i}}^{n}\right)\right] \Delta t \\
& \phi_{1}=\frac{\gamma-1}{2}\left(\frac{h}{\delta_{\text {mil }}}\right)\left(\frac{1}{\rho_{\text {mil }}}\right)\left(\frac{c_{p}}{c_{\text {mil }}}\right) \\
& \phi_{2}=\frac{0.04}{\gamma-1} \operatorname{Pr}^{-0.4} \operatorname{Re}^{-0.2} \phi_{1}\left(\frac{L}{b}\right)\left(\frac{R}{L}\right)^{0.6}\left(\frac{P_{c \text { sv }}^{\mathrm{n}} \omega L}{a^{*}}\right)^{0.8}
\end{aligned}
$$

where, $\delta_{\text {wall }}, c_{\text {wall }}$, and $p_{\text {wall }}$ are the wall thickness, specific heat and non-dimensional density, respectively; $c_{p}$ is the gas specific heat at constant pressure (assumed constant), $R$ is the rotor radius, $\rho_{\mathrm{cov}}$ is the non-dimensional center cavity gas density, $\mathrm{s}_{3}$ in is the third term of the intermediate region source vector (Eqn. 4), and $\omega$ is the rotor speed. The coefficient $\phi_{2}$ is the product of the Fourier and Biot moduli ${ }^{8}$ for the outer surface of the wall. The heat transfer coefficient in $\phi_{2}$ was derived from a correlation for steady turbulent flow over a flat plate ${ }^{11}$ with the flat plate length replaced by the rotor circumference. Use of a crude integration scheme in Eqn. 10 while using a time accurate scheme for Eqn. 7 is justified since the time constants associated with transients in the wall temperature (and those of the gas in the center cavity and combustor to be discussed below) are much larger than the passage wave transit time or even the time for one complete wave cycle.

\section{Center Cavity}

The gas state in the rotor center cavity is also integrated using a simple lumped capacitance technique. Changes in the gas state arise due to heat transfered from the rotor inner and outer wall surfaces and due to leakage from the passage ends. The cavity density and pressure may be integrated using continuity and energy equations written in the form

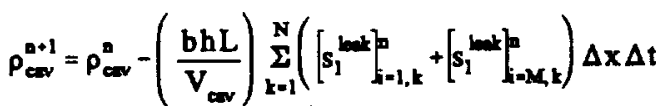

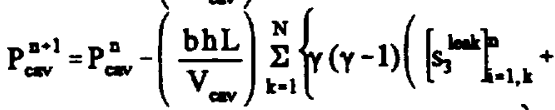

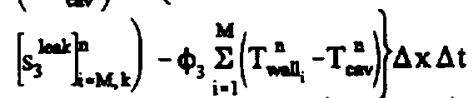

$$
\begin{aligned}
& \phi_{3}=0.04 \gamma \operatorname{Pr}^{-0.4} \operatorname{Re}^{-0.02}\left(\frac{L}{h}\right)\left(\frac{R}{L}\right)^{0.6}\left(\frac{P_{c \text { cov }}^{\mathrm{a}} \omega \mathrm{L}}{\mathrm{a}^{*}}\right)^{0.8}
\end{aligned}
$$

where $N$ is the number of passages, $M$ is the last computational cell in the passage computing domain, $b$ is the passage width, $V_{\mathrm{cav}}$ is the volume of the center cavity, and the subscript $k$ refers to the individual passages. The wave rotor casing is assumed adiabatic. The gas in the center cavity is assumed to have negligible kinetic energy.

\section{Combustor}

The combustor density and pressure are modeled similarly to the center cavity except that there is an allowance for heat addition in the energy equation, i.e.

$$
\begin{aligned}
& \rho_{\infty+\infty}^{n+1}=P_{\infty \infty ⿻}^{n}-\left(\frac{b h L}{V_{\infty+\infty}}\right)\left\{\sum_{k=1}^{N_{\infty}}\left[F_{1}\right]_{i=0, k}^{n}-\sum_{k=1}^{N_{\infty}}\left[F_{1}\right]_{i=M+1, k}^{n}\right\} \Delta t
\end{aligned}
$$

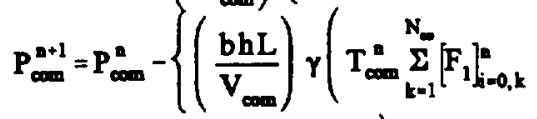

$$
\begin{aligned}
& \left.\left.-T_{a}^{n} \sum_{k=1}^{N}\left[F_{1}\right]_{i=M+1, k}^{n}\right)-\frac{(\gamma-1) Q L}{V_{\operatorname{com}} p^{*} a^{*}}\right\} \Delta t
\end{aligned}
$$

where $Q$ is the heat addition rate, $V_{\text {com }}$ is the combustor volume, $T_{\text {com }}$ is the non-dimensional combustor exit temperature, and $T_{c}$ is the non-dimensional combustor inlet stagnation temperature obtained from

$$
T_{a i}^{a}=\frac{\sum_{k=1}^{N_{d}}\left[F_{3}\right]_{j-M, k}^{D}}{\sum_{k=1}^{N}\left[F_{1}\right]_{i=M, k}^{p}}+\frac{\gamma-1}{2}\left(\frac{\omega R}{a^{*}}\right)^{2}
$$

Refering to Fig. 1, the integers $\mathrm{N}_{\mathrm{co}}$ and $\mathrm{N}_{\mathrm{c}}$ indicate summations over those passages which are exposed (or partially exposed in the case of finite opening time) to the combustor outlet port and combustor inlet port respectively.

The combustor pressure and temperature obtained from eqns. 12 and 13 are used as updated inlet stagnation conditions for those rotor passages which are exposed to the combustor outlet port at the next time step (i.e. inflow boundary conditions, see Refs. 5 and 7). The passages exposed to the combustor inlet port (i.e. outflow boundary conditions) require an updated static pressure. This is obtained by first estimating the stagnation pressure for the gas just upstream of the combustor using the following equation

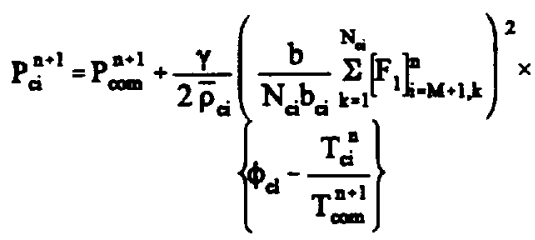

where $b_{c i}$ is the circumferential span of the combustor inlet port, $\bar{p}_{\mathrm{d}}$ is the mixed static density of the combustor inlet port flow (see appendix 1), and $\phi_{\mathrm{cl}}$ is a constant value 
greater than 1 which provides a so called 'cold' loss in addition to the loss which is incurred by simply heating the gas at constant velocity and static pressure as is assumed in this combustor model. The value of $\phi_{\mathrm{el}}$ used here is 2.05 . With the combustor inlet stagnation pressure known, the estimated rotor face static pressure required by the model is obtained using the following steady isentropic relation

$$
P_{d i}^{2+1}=P_{d}^{q+1}\left(\frac{\bar{p}_{d}^{Z}}{\bar{P}_{d}^{2} T_{d i}^{Z}}\right)^{\frac{Y}{r-1}}
$$

where $\overline{\mathbf{p}}_{\mathrm{a}}$ is the mixed static pressure of the combustor inlet port flow (see Appendix 1).

\section{Boundary Conditions}

Implementation of boundary conditions in the model is discussed in detail in refs. 5-7 and will not be presented here. Suffice it to say that the boundary conditions account for the effect (loss) of finite opening time as each passage enters and exits a port region, and the effect of flow turning when the nominally steady flow in the port is not aligned with the flow in the wave rotor passages. Furthermore, the boundary conditions allow computations to continue in extreme off design situations where portions of the port flows may be reversed from their intended directions. The torque on the rotor may be calculated at any instant of time by summing the product of mass flow rate and the change in tangential velocity from the duct to the adjacent computational cell over all the passages with inflow.

\section{Example Wave Rotor Description and Steady State Behavior}

The wave rotor chosen for this paper has been 'designed' as a 4 port topping cycle for a $2.3 \mathrm{~kg} / \mathrm{s}(5 \mathrm{lbm} / \mathrm{s})$ engine, with an upstream compressor pressure ratio of approximately 8 . The design technique used is described in Ref. 4. Table 1

Table 1 Wave rotor dimensions and design performance

\begin{tabular}{lll}
\hline Mean Rotor Radius & $8.15 \mathrm{~cm}$. & (3.2 in.) \\
Rotor Length & $15.24 \mathrm{~cm}$ & $(6.0 \mathrm{in})$. \\
Rotor Passage Height & $2.24 \mathrm{~cm}$. & $(0.88 \mathrm{in})$. \\
Rotational Speed & $16800 \mathrm{rpm}$ & \\
Cycles $/$ Revolution & 2 \\
Number of Passages & 52 & \\
Mass Flow Rate & $2.3 \mathrm{~kg} / \mathrm{s}$ & $(5.0 \mathrm{lbm} / \mathrm{s})$ \\
$\mathrm{P}_{4} / \mathrm{P}_{1}$ (Fig. 1 or 2) & 1.22 & \\
$\mathrm{~T}_{4} / \mathrm{T}_{1}$ & 2.21 \\
\hline \hline
\end{tabular}

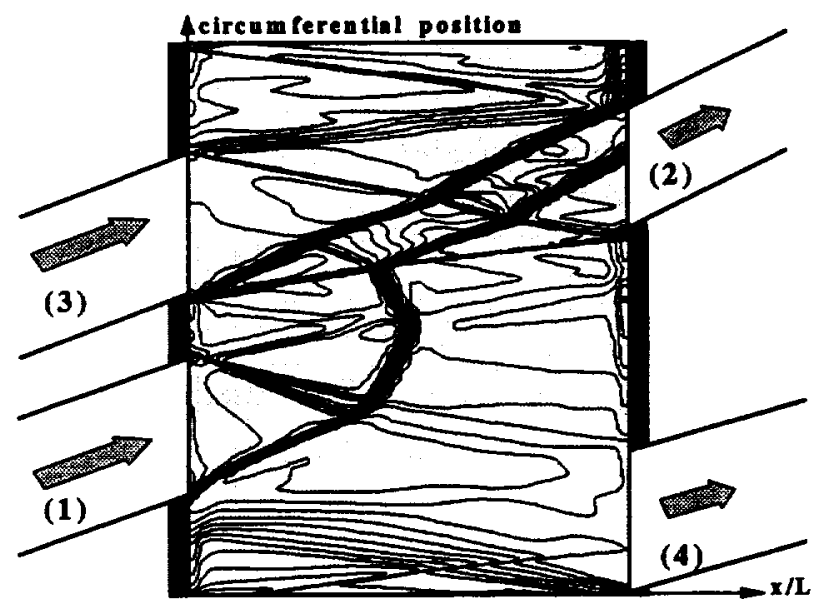

Figure 2 Design point density contours

shows the relevant dimensions and design point performance. Fig. 2 illustrates the design point wave pattern using contours of density plotted as a function of circumferential and axial distance. This may be thought of as a time averaged view (i.e. averaged over the time required for a passage to open) of the standing wave pattern that a stationary observer would see. Although not directly related to dynamic performance, it is interesting to note that the flow going to the combustor (port 2) is a mixture of both compressed fresh air from the inlet (port 1) and hot gas that did not escape from the rotor during the exhausting process (port 4). This 'exhaust gas recirculation' is a unique aspect of this particular type of four port cycle. There are other configurations in which it does not occur ${ }^{3}$. It is not known at this point whether it represents an advantage or disadvantage in terms of combustor design and/or pollution control.

\section{Steady state performance}

Before discussing dynamic results, it is worthwhile to briefly review the steady state wave rotor characteristics. Doing so provides a reference against which to measure the deviations from normal operation exhibited by the dynamic simulations. Assuming perfect gas behavior and constant dynamic viscosity, the steady state performance of a wave rotor topping cycle can be described in terms of the ratio of specific heats, $\gamma$, and following three dimensionless variables:

$$
\begin{aligned}
& N_{c}=\omega \sqrt{\frac{A_{i}}{R_{g} T_{i g_{c}}}} \\
& \dot{\mathrm{m}}_{\mathrm{c}}=\frac{\dot{\mathrm{m}}_{\mathrm{i}}}{\mathrm{A}_{\mathrm{m}} \mathrm{P}_{\mathrm{in}}} \sqrt{\frac{\mathrm{R}_{\mathrm{g}} \mathrm{T}_{\mathrm{i}}}{\mathrm{B}_{\mathrm{c}}}} \\
& Q_{c}=\frac{Q}{A_{i=1} P_{i=} \sqrt{R_{s} T_{i n} B_{c}}}
\end{aligned}
$$

where $\dot{\mathrm{m}}_{\mathrm{m}}, \mathrm{A}_{\mathrm{in}}, \mathrm{P}_{\mathrm{in}}$, and $T_{\mathrm{in}}$, are the wave rotor inlet (port 1 


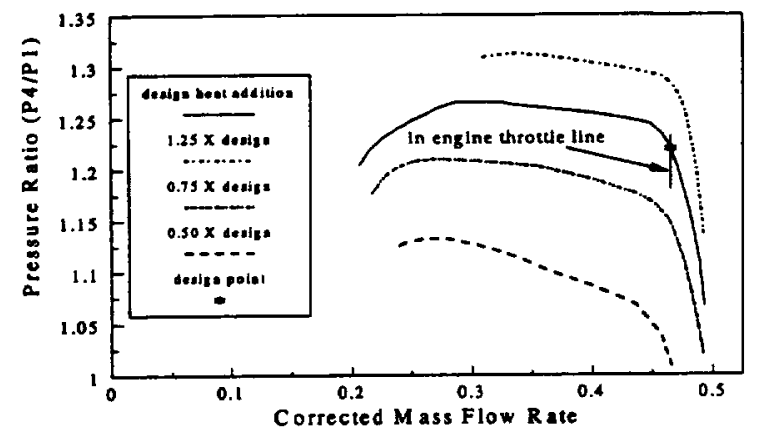

Figure 3 Constant speed, steady state performance map

in Fig. 2) mass flow rate, cross sectional area, stagnation pressure and stagnation temperature respectively, $R_{g}$ is the real gas constant and $g_{c}$ is the Newton constant. The first two variables are essentially corrected speed and corrected mass flow rate. The last variable, corrected heat addition, is not normally used to describe turbomachinery performance (although it could be) because the compressor and turbine components are usually considered separately. This is not possible on the wave rotor however, since compression and expansion occur on the same device and are highly coupled. Given $\gamma$ and the variables of Eqn. 16, any other variable of interest can be represented as a dimensionless function of these four. For instance, from a steady-state topping cycle operability point of view, one would be interested in knowing the stagnation pressure and temperature ratios across the entire wave rotor as functions of these variables. Refering to Fig. 1, this would be $P_{\downarrow} / P_{1}$ and $T_{4} / T_{1}$. If, as is done in the model, $\gamma$ is assumed constant, then one independant variable would be eliminated. A multi-dimensional map would still be required however, which is difficult to envision. It has been observed in cycle deck studies of the type of wave rotor topping cycle under consideration here ${ }^{3}$ that, for small turboshaft engines, optimal performance is found along a constant corrected speed line for most of the operating range (neglecting startup and idle modes). Furthermore, although the effect that off-design flow turning has on performance can be large ${ }^{7}$, the amount of work done on the gas is relatively small compared to the heat addition. If this shaft work is neglected, then the temperature ratio may be obtained from the corrected mass flow rate and heat addition as

$$
\frac{T_{4}}{T_{1}}=1+\left(\frac{\gamma-1}{\gamma}\right) \frac{Q_{c}}{\dot{m}_{c}}
$$

Thus, the desired wave rotor performance may be expressed on a single plot which shows overall pressure ratio as a function of corrected mass flow rate for different families of corrected heat addition. Such a map is shown in Fig. 3 for the particular wave rotor described above. This map was generated using the single passage, steady

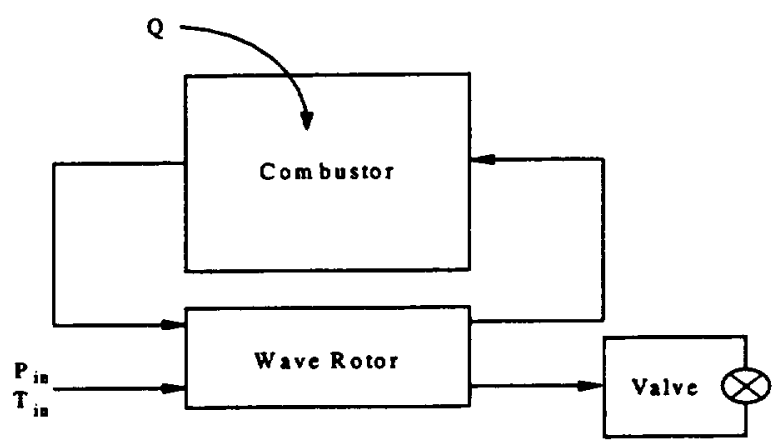

Figure 4 Block schematic of simulation

state model described in Refs. 1, 5-7 and verified at several points using the present model. Also shown in the figure is the design operating point, and a line representing the locus of normal operating points in an engine environment ${ }^{3}$ for a range of throttle positions (i.e. heat addition levels).

\section{Dynamic Results}

The arrangement of the transient simulation is shown in block schematic form in Fig. 4. The valve attached to the exhaust port (4) is described in Appendix 2. It is assumed to exhaust to standard atmospheric conditions. The wave rotor inlet is assumed to be at conditions representative of the upstream compressor exit. In this numerical 'test cell' environment the exhaust valve area and heat addition can be independently altered (i.e. they are inputs) and any other wave rotor variable of interest can be monitored. In addition the combustor, valve, and center cavity volumes can be altered in order to isolate their effect on transient phenomena.

\section{Transient Responses to Step Inputs}

The computed wave rotor response to a step change in heat addition is shown in Figs. 5 and 6. The model ran for 20 msec. of simulation time at the design point. At that time the heat addition rate was abruptly cut to half of the design value. At $200 \mathrm{msec}$. of simulation time the heat addition rate was abruptly raised back to the design value and held there for the remainder of the $400 \mathrm{msec}$ simulation. The ratios of passage volume to the center cavity, combustor, and valve volumes in Eqns. 11, 12, and 23 were 0.0093, 0.0037 , and 0.018 respectively. The mass flow rates in each of the ports are shown in Fig. 5. These have been normalized by the inlet (port 1 in Fig. 1) area, stagnation pressure, and stagnation temperature as in Eqn. 16. For the inlet only, this is the corrected flow and corresponds to the $x$-axis of Fig. 3. Figure 6 shows non-dimensional stagnation pressures and temperatures in the combustor and exhaust port. Since the inlet stagnation state has been used to non-dimensionalize, the exhaust pressure in this figure 

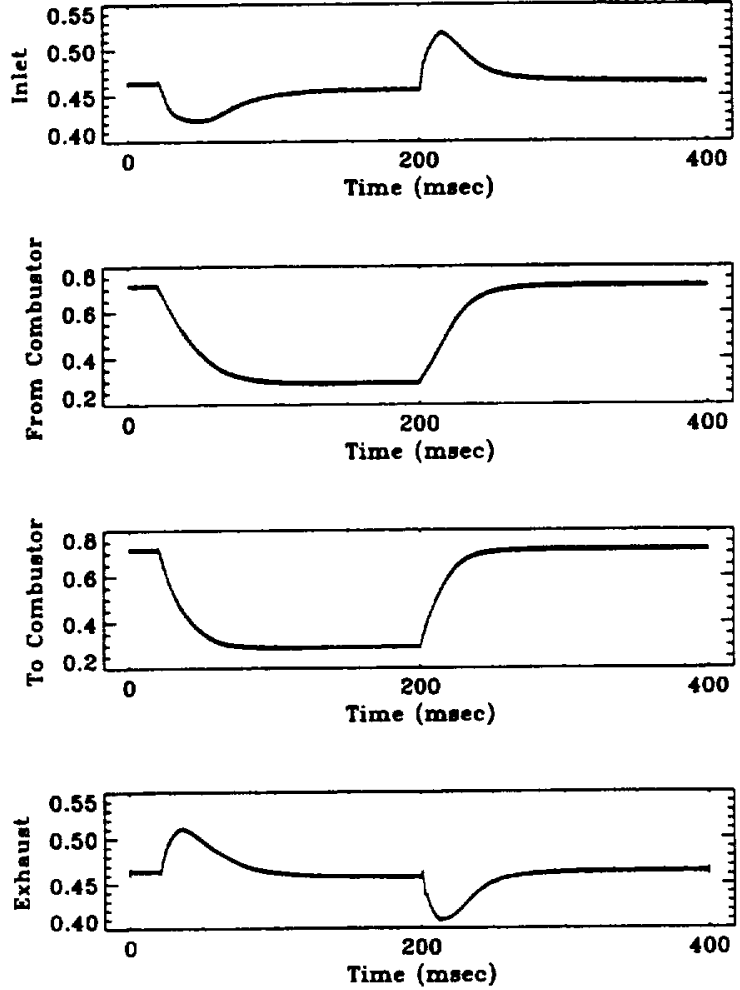

Figure 5 Step heat addition transient port mass flow rates
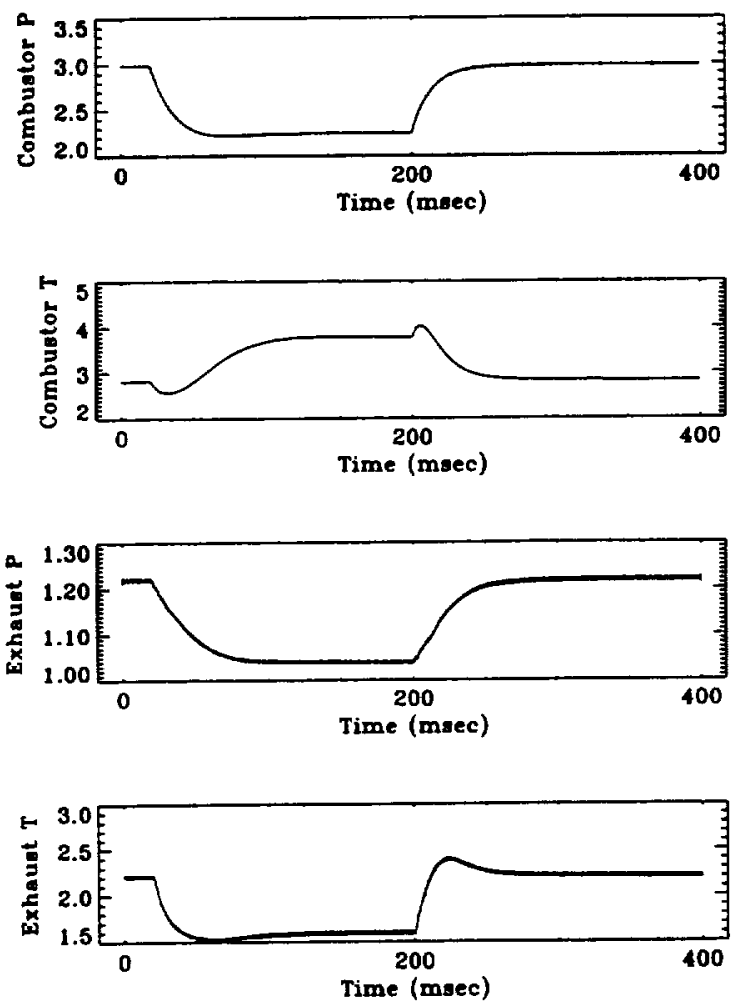

Figure 6 Step heat addition transient pressures and temperatures
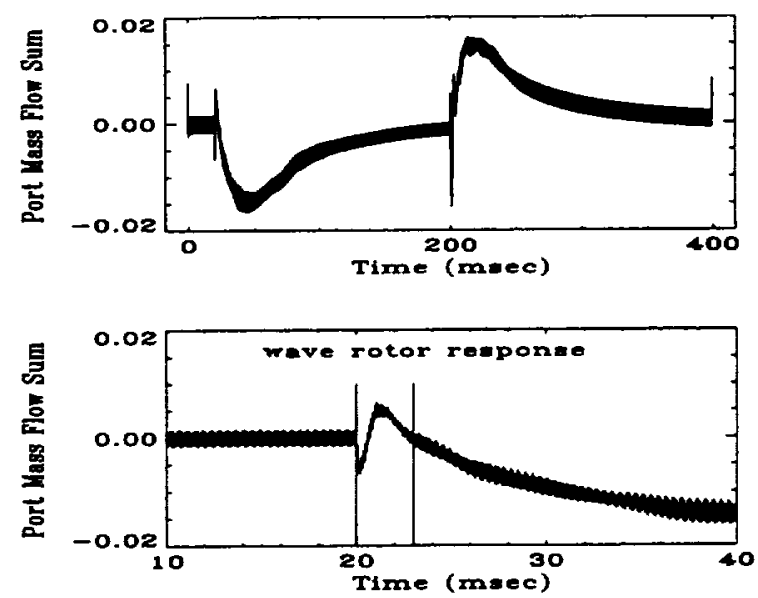

Figure 7 Step heat addition transient port mass flow rate summation

corresponds to the y-axis of Fig. 3. The simulation data was output at a time interval of $0.01 \mathrm{msec}$ (every 6 nondimensional time steps) then smoothed using a 5 point average in order to partially remove the high frequency oscillations which occur due to finite passage opening time. For reference, one rotor revolution (two wave cycles) is approximately $3.6 \mathrm{msec}$. The transient behavior seen in this simulation example is due almost entirely to the volume dynamics associated with the combustor, center cavity, and valve. That is to say that the wave rotor is essentially operating in steady-state even though the inlet and exhaust mass flow rates do not match one another, nor do the flow rates to and from the combustor. This may be seen in Fig. 7 which shows the sum of the normalized mass flow rates to and from all of the ports as a function of time. The upper plot shows the entire simulation period, while the lower plot shows only the first $52 \mathrm{msec}$. If mass were being stored in the wave rotor (or center cavity), this sum would be large; however, it is seen that the sum never exceeds 0.02 , whereas the difference between inlet and exhaust mass flow rates (Fig.5) reaches values as high as 0.1 . The relatively fast response of the wave rotor itself can be seen on the lower plot of Fig. 7 between 20 and 23 msec. The first minimum on this plot (between 20 and 20.5 msec.) represents the readjustment time of the waves. The maximum which follows, of somewhat longer duration, represents the convection time for a particle passing through the rotor. The remaining transient response is due to the volume dynamics of the center cavity.

It is interesting to note that during this transient operation the combustor pressure (i.e. the compression portion of the cycle) decreases with decreasing inlet flow when the heat addition rate is reduced, and vice versa when the heat addition rate is increased. In a conventional gas turbine engine, the initial transient behavior would be the opposite 

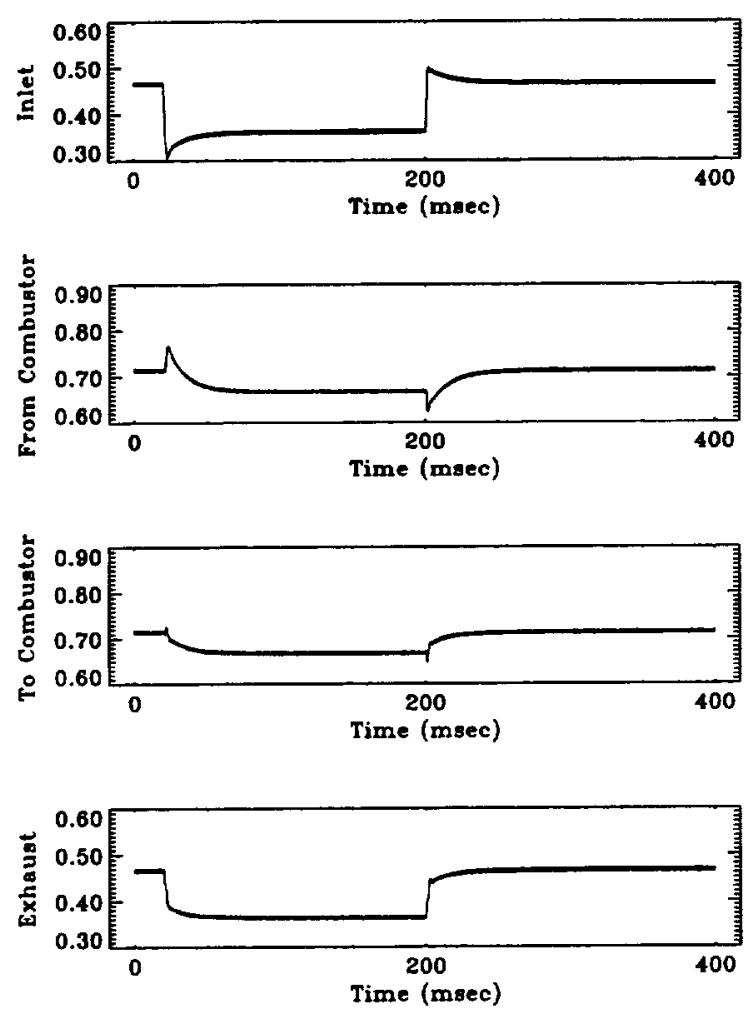

Figure 8 Step exhaust valve area change transient port mass flow rates
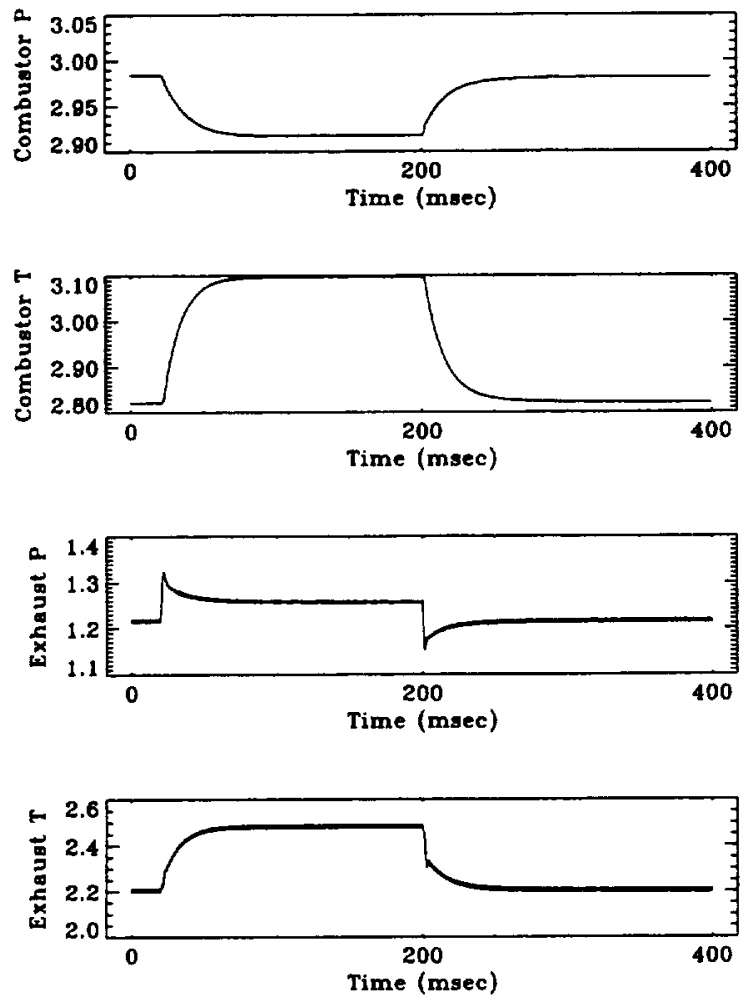

Figure 9 Step exhaust valve area change transient pressures and temperatures
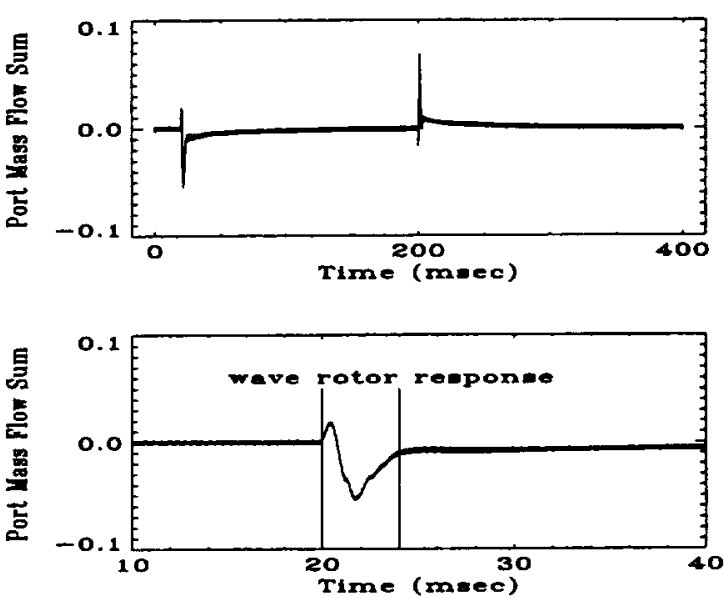

Figure 10 Step exhaust valve area change transient port mass flow rate summation

way.

The wave rotor mass flow, pressure, and temperature response to a step change in the exhaust valve area are shown in Figs. 8 and 9. As in the previous simulation the model ran for $20 \mathrm{msec}$ of simulation time at the design point. At that time the exhaust valve area was abruptly cut to $80 \%$ of the design value. At $200 \mathrm{msec}$ of simulation time the valve area was abruptly increased back to the design value and held there for the remainder of the 400 msec. simulation. The ratios of passage volume to the cavity, combustor, and valve volumes were the same as in the previously described simulation. Fig. 10 shows the same type mass flow summation as Fig. 7. Again it can be seen that the response of the wave rotor is very fast relative to the various volume dynamics. With regard to Fig.3, it can be seen that both this and the previously presented transient represent situations in which the wave rotor is operating far from the normal range. It is encouraging from a modeling perspective that the simulation can calculate such severe transients. More importantly however, it is encouraging that the wave rotor appears to be so robust.

\section{Instabilities}

Although it is not yet possible to experimentally verify the results of the wave rotor model described above, it is at least possible to see if it follows expected dynamic trends. One such trend would be a phenomenon akin to surge which, with reference to Fig. 3, would occur when the wave rotor is operating somewhere on the far left side of the constant heat addition curves where the slopes of the performance curves are positive ${ }^{12}$. It should be pointed out that this region is far from the normal operating regime of the wave rotor. Furthermore, steady-state results indicate that long before it could reach this point the combustor temperatures would become unacceptably high (i.e., 5 times the inlet temperature). Nevertheless, attempting to operate the model here provides a good test for the 

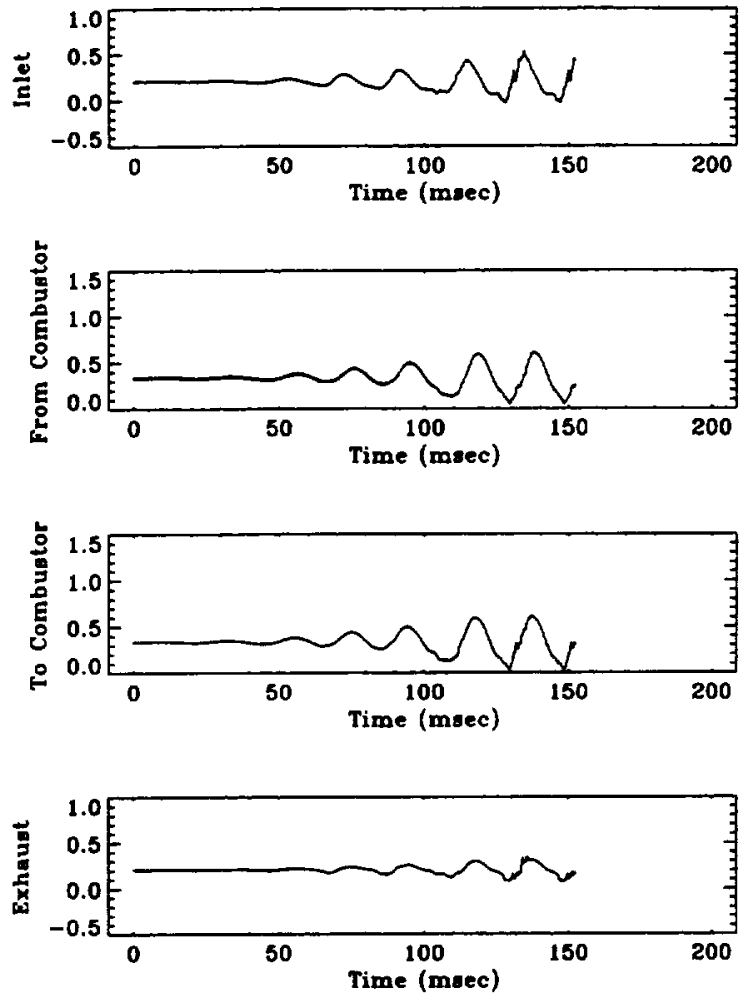

Figure 11 Unstable surge port mass flow rates
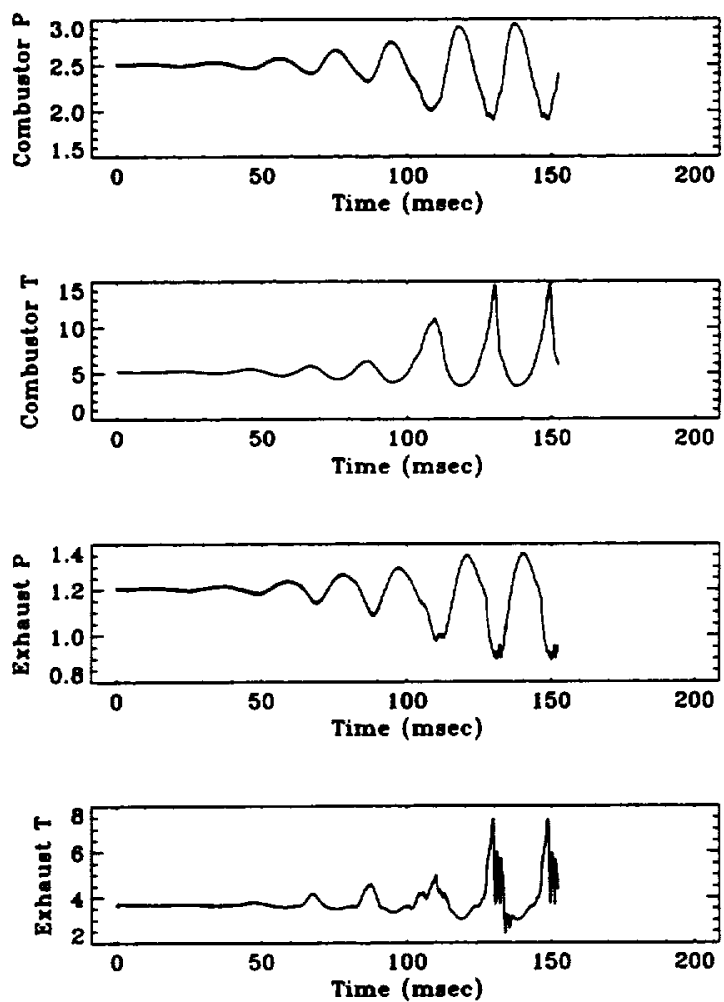

Figure 12 Unstable surge pressures and temperatures

numerics. Figures 11 and 12 show a time history of the port normalized mass flows, pressures, and temperatures during a simulation which began at the design speed and heat addition rate, but with the exhaust valve area set to $58 \%$ of the design point value. The valve position at which this instability begins is dependent on the combustor and valve (and possibly center cavity) volumes. It was found that the simulation was stable at this operating point for the passage to volume ratios used in the previous simulations. The exact relationship between volume sizes and the onset of this instability has not been fully explored; however, it was found that decreasing the combustor volume and increasing the valve volume both appear to shift the point of instability further to the right of Fig. 3 (i.e., larger exhaust valve openings). Thus, the data for Figs. 11 and 12 were obtained by first running the simulation to steady state using the original center cavity, combustor, and valve passage to volume ratios of $0.0093,0.0037$, and 0.018 respectively. The passage to volume ratios of the combustor and valve were then changed to 0.037 and 0.0062 respectively and the simulation was restarted with initial conditions from the last time step of the stable simulation configuration. Fig. 12 shows stagnation pressure and temperatures in the combustor and exhaust ports for this simulation. Since the combustor temperature reaches very high values it was necessary to substantially reduce the size of the time step in the computional scheme. It was found that a non-dimensional value of 0.0015 (compared to 0.006 used in the other simulations) maintained a stable computational scheme.

\section{Ereewheeling Rotor}

The results shown thus far are for a wave rotor which runs at constant speed and is thus driven by some external source. It is possible however for the wave rotor to be selfdriven or freewheeling ${ }^{13}$. If bearing drag, friction between the rotor and endwalls, and friction between the rotor and casing are neglected then the only source of torque on the rotor arises from the flow turning required to bring flow on board the rotor from the ducts. At the design point, the inlet ducts would be so angled such that this would presumably be zero. At any other operating point however, the rotor will either acclerate or decelerate until the net torque is zero. In this mode of operation the corrected speed becomes a dependent variable and Eqn. 17 becomes absolutely valid. It is noted that in steady-state operation there is no guarantee that the speed which the rotor settles out to at any operating point (other than the design point) is optimal as far as the timing of the internal wave processes. Fig. 13 shows the steady-state performance map for the freewheeling version of the same wave rotor used in the fixed speed examples. Note that the design points of the two rotors are the same.

Figure 14 shows the wave rotor response to a step $50 \%$ reduction in the heat addition rate initiated $2.0 \mathrm{msec}$ after the simulation began. The time scale of this simulation is very long in comparison to the others which have been shown previously. This is due to the relatively slow rotor inertial dynamics which are made even slower by the fact that the flow turning process generates fairly low torque 


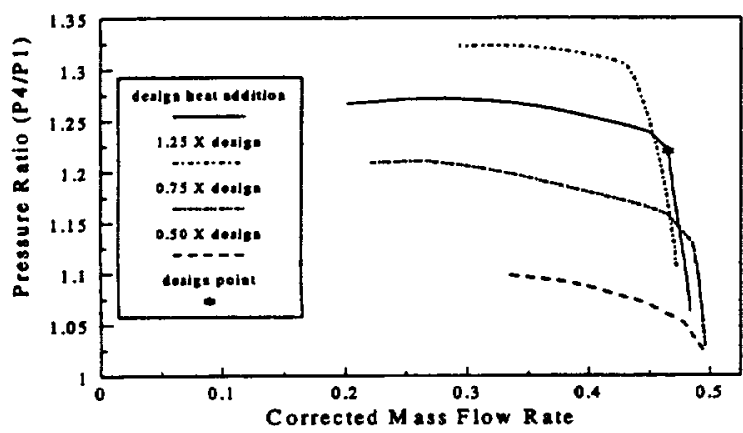

Figure 13 Freewheel steady state performance map
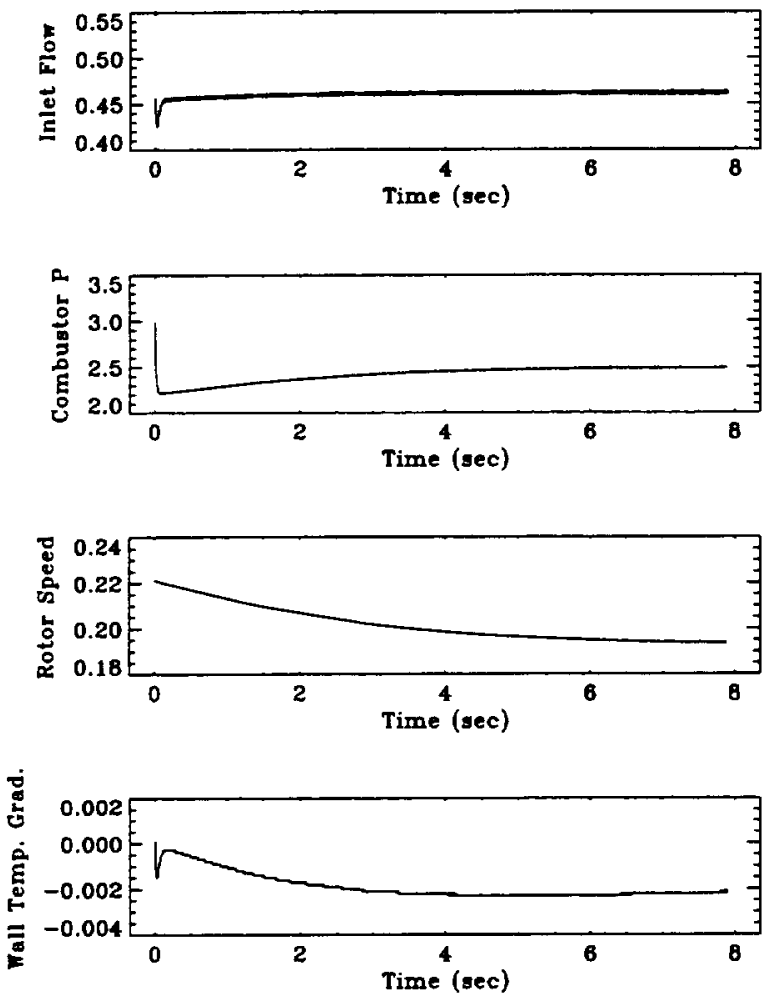

Figure 14 Step change in heat addition transient, freewheeling wave rotor

(unlike conventional turbomachinery in which torque is the primary means of work transfer). In order to produce the data for Fig. 14 without using excessive computing resources, a very crude computational spacing of $\Delta x=0.1$ was used with a corresponding time step of $\Delta t=.03$. Furthermore, the data was output only every $0.36 \mathrm{msec}$. No systematic study has been performed to date on the model to determine the 'best' grid resolution for simulation purposes; however, it is believed that these values of the time step and spacing are sufficient to reasonably demonstrate the rotordynamic phenomenon of interest here. The inertia of the rotor was estimated using steel with a density of $7860 \mathrm{~kg} / \mathrm{m}^{3}$ and assuming that the only contributing mass was that of the inner and outer cylinders of the rotor. These were taken to be $0.76 \mathrm{~cm}$. in thickness. The figure shows plots of the inlet corrected flow rate, nondimensional combustor pressure, rotor corrected speed, and the summation over all of the computational cells of the rates of change in non-dimensional wall temperature. This last plot is included as a very crude measure of the predicted time scale of the heat transfer effects in the wave rotor. The fact that a relatively large gradient still exists at the end of the simulation indicates the scale is considerably longer than even the rotor dynamic time scale, which is itself two orders of magnitude larger than the volume dynamic time scales, and three to four orders larger than the gasdynamic time scales.

It can be seen in Fig. 14 that the wave rotor performance is fairly insensitive to changes in rotational speed. Thus, although the rotor speed does not reach steady state until 8 sec. after the step reduction in heat addition rate, the combustor pressure and inlet flow have reached nearly steady state values in the same approximately $50 \mathrm{msec}$. time frame as the previous fixed speed transient examples. This is in contrast to a conventional turbomachinery core which would require time scales on the order of seconds to complete the same transient.

\section{Concluding Remarks}

A numerical model has been described which is capable of computing both steady state and transient flow fields in a wave rotor. Since it is a one dimensional model it is relatively fast. The grid resolution used for the constant speed simulations required approximately 143 seconds of CPU time for each millisecond of simulated time on a SunSPARC 10 workstation. The freewheeling simulation ran at approximately 25 times that rate due to a 5 times increase in the time step size and a 5 times reduction in the number of computational cells. Although no experimental transient wave rotor data is available with which to compare, the model predicts results which qualitatively meet expectations, including the onset of instabilities in the far off-design operating regime.

The preliminary results presented in this paper suggest that the wave rotor response to transient input is an order of magnitude faster than the external volume dynamics and approximately 3 orders of magnitude faster than the freewheeling rotor dynamics. Furthermore, it appears that the wave rotor is stable over a wide range of transient operations.

Ultimately, the dynamic performance of the wave rotor topping cycle can only be properly assessed in an integrated engine simulation environment since the behavior of the surrounding turbomachinery will have a large influence on the wave rotor. This is the intended direction of future research in the type of one-dimensional modeling presented in this paper. 
1. Paxson, D. E., "A Comparison Between Numerically Modelled and Experimentally Measured Loss Mechanisms in Wave Rotors," presented at The 29th Joint Propulsion Conference, Monterey, CA, paper \# AIAA-93-2522, June, 1993, also NASA TM 106279, 1993.

2. Wilson, J., and Paxson, D. E., "Jet Engine Perfomance Enhancement Through The Use of a Wave-Rotor Topping Cycle," NASA TM 4486, October, 1993.

3. Welch, G. E., Jones, S. M., and Paxson, D. E., "Wave Rotor Enhanced Gas-Turbine Engines," AIAA-952799, July, 1995.

4. Wilson, J. and Paxson, D. E., "Optimization of Wave Rotors for use as Gas Turbine Engine Topping Cycles," presented at The 1995 SAE Aerospace Atlantic Conference, Dayton, Ohio, paper \$951411.

5. Paxson, D. E., "A General Numerical Model for Wave Rotor Analysis," NASA TM 105740, July, 1992.

6. Paxson, D. E., "An Improved Numerical Model for Wave Rotor Design and Analysis," presented at The 31st Annual Aerospace Sciences Meeting, Reno, NV, paper \#AIAA-93-0482, January, 1993, also NASA TM 105740, January, 1993.

7. Paxson, D. E. And Wilson, J., "Recent Improvements to and Validation of the One Dimensional NASA Wave Rotor Model," NASA TM 106913, May, 1995.

8. Holman, J. P., Heat Transfer, Sth edition, McGrawHill Publishing Company, 1981.

9. Egli, A., "The Leakage of Steam Through Labyrinth Seals," Trans. ASME, Vol. 57, 1935, pp. 115-122.

10. Roe, P. L., "Characteristic Based Schemes for the Euler Equations," Annual Review of Fluid Mechanics, 1986, vol. 18, pp 337-65.

11. Kays, W. M., and Crawford, M. E., Convective Heat and Mass Transfer, McGraw-Hill Book Company, 1980.

12. Greitzer, E. M., "The Stability of Pumping Systems," Transactions of the ASME Journal of Fluids Engineering, Vol. 103, June 1981, pp.193-242.

13. Zehnder. G., Mayer, A., Matthews, L., "The Free Running Comprex," presented at the SAE International Congress and Exposition, Detroit Michigan, Feb. 27-March 3, 1989, paper \# 890452.
Mixing calculations in the outflow ports account for the losses incurred due to non-uniformities in the flow. Flow in inlet ports is assumed isentropic. The non-uniformities accounted for in the mixing calculation arise from several sources including passage opening and closing, mistimed waves impinging on the port during off- design operation, and broad expansion waves which, even on-design, reflect from some ports and cause non-uniformities in the velocity profile. In off-design situations the flow emerging from the rotor must also be turned by the port walls since it is not necessarily aligned with them. The two processes (mixing and turning) generally occur simultaneously and may require a length many times the port width to be completed. In the model they are assumed to occur separately. Furthermore, since there is no accounting at present for the duct length leading from the ports, they are assumed to occur instantaneously. The mixing process is assumed to occur in the rotor frame of reference and the turning process is assumed to be isentropic. These simplifications, though quite extreme, have yielded good results when compared with experiments (at least in steady-state operation). The non-dimensional mixed relative static conditions are obtained as follows

$$
\begin{aligned}
& \bar{u}_{r}=\frac{\gamma \phi_{m}-\sqrt{\left(\gamma \phi_{m}\right)^{2}-2(\gamma+1) \phi_{g} \phi_{m}}}{(\gamma+1) \phi_{m}} \\
& \bar{p}_{r}=\frac{\phi_{m}}{N \bar{u}_{r}} \\
& \bar{p}_{r}=\frac{\gamma}{N}\left(\phi_{m}-\phi_{m} \bar{u}_{r}\right)
\end{aligned}
$$

where

$$
\begin{aligned}
& \phi_{m}=\sum_{k=1}^{N} p_{0} u_{0} \\
& \left.\phi_{m=0} \equiv \sum_{k=1}^{N}\left(\frac{p_{0}}{\gamma}+p_{0} u_{\theta}^{2}\right) \frac{A_{0}}{A_{p}}+\sum_{k=1}^{N-N}\left(\frac{p_{0}}{\gamma}+p_{0} u_{0}^{2}\right)\right] \\
& \phi_{0} \equiv \sum_{k=1}^{N} \rho_{0} u_{0}\left(T_{0}+\frac{\gamma-1}{2} \frac{u_{0}^{2}}{2}\right) .
\end{aligned}
$$

Here, the subscript 0 refers to the image cell adjacent to the port. The subscript $e$ in the expression for $\phi_{\text {mo }}$ refers to a fictitious exit plane of the image cell when the passage is partially open (see Fig. A1 and Ref. 6). The summations occur over those passages which are exposed to the port, $N$ and the subscript po refers to those passages which are partially open. The ratio of $A_{e}$ to $A_{p}$ is that of the passage area exposed to the port to the fully open area. The absolute stagnation quantities are then obtained from the mixed, relative quantities using 


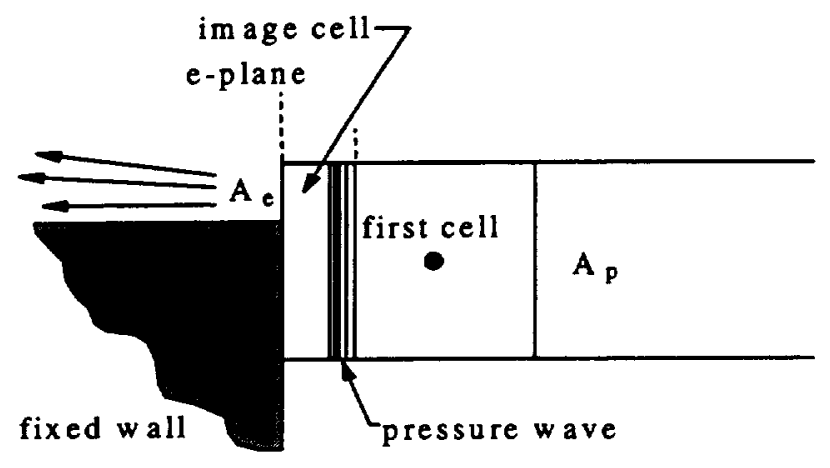

Figure A1 Partially opened passage outflow

$$
\begin{aligned}
& T^{0}=\left(\frac{\phi_{G}}{\phi_{m}}+\frac{\gamma-1}{2}\left(\frac{\omega R}{a^{*}}\right)^{2}\right) \\
& P^{0}=\bar{P}_{r}\left(\frac{T^{0}}{\bar{T}_{r}}\right)^{\frac{r}{\gamma-1}} .
\end{aligned}
$$

The mixed absolute static conditions (i.e after turning) are obtained as follows. Referring to Fig. A2, which shows a port and the approaching mixed relative flow, the following steady continuity and energy equations may be written

$$
\begin{aligned}
& \bar{p}_{a} \bar{u}_{a}=\frac{\bar{p}_{t} \bar{u}_{s}}{\cos (\beta)} \\
& \frac{\bar{p}_{a}}{\bar{p}_{a}}+\frac{\gamma-1}{2} \frac{\bar{u}_{a}^{2}}{2}=T^{0} .
\end{aligned}
$$

Using the isentropic relation $\frac{p}{p^{\gamma}}=$ constant, and combing eqns. 19 , the following equality may be written

$$
\begin{aligned}
& q_{1} \bar{p}_{a}^{\frac{\gamma-1}{\gamma}}+q_{2} \bar{p}_{a}^{\frac{-2}{\gamma}}-T^{0}=0 \\
& q_{1}=\frac{\bar{p}_{r}^{\frac{1}{\gamma}}}{\bar{p}_{r}} \\
& q_{2}=\frac{\gamma-1}{2}\left(q_{1} \frac{\bar{p}_{r} \bar{u}_{r}}{\cos (\beta)}\right)^{2} .
\end{aligned}
$$

The roots of this equation (found easily using Newton iteration) are the sub and supersonic values of the absolute static pressure. The sub-sonic value is chosen and the absolute static density and velocity are found using eqns. 19.

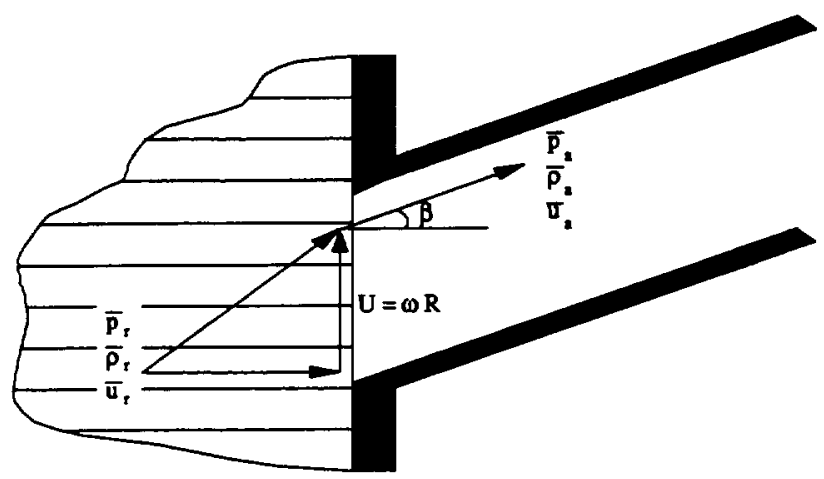

Figure A2 Isentropic flow turning schematic

\section{Appendix 2Numerical Valve Simulation}

The wave rotor exhaust valve and associated plenum are simulated in much the same fashion as the combustor. Since there is no heat addition however, and the only variable of interest is the static pressure at the port exit, only the energy equation is used. It is written as follows

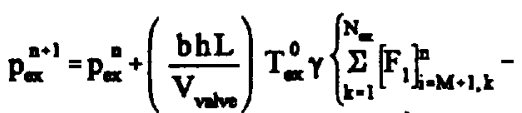

$$
\begin{aligned}
& \left.\gamma_{2}\left(\frac{A_{\text {valo }}}{b h}\right) \frac{P_{a}^{a}}{\sqrt{T_{a}^{0}}} f\left(\frac{P_{w}}{P_{a x}^{a}}\right)\right\} \Delta t
\end{aligned}
$$

where the subscript ex refers to the exit port (port 4 in Fig. 1 ), and the subscript ve refers to the valve exit, which is taken to be standard atmosphere in this case. The function $f$ is the same St. Venant's equation described in Eqn. 6 . The updated pressure in this equation is used as an outflow boundary condition for the passages which are exposed to the exhaust port (port 4 in Fig. 1). 
Public reporting burden for this colbction of information is estimated to average 1 hour per response, including the time for reviewing instructions, searching existing data sources. gatherting and malntaining the data needed, and completing and reviewing the collection of information. Send comments regarding this burden estimale or any other aspect of this collection of information, including suggestions for reducing this burden, to Washington Headquanters Services. Directorale tor Information Operations and Reports. 1215 Jefferson Davis Hiptway. Suite 1204. Arlingion. VA 22202-4302, and to the Otlice of Management and Budget, Papenwork Reduction Projoct (0704-0188), Washington, DC 20503.

1. AGENCY USE ONLY (Leave blank)

4. TIILE AND SUBTTIEE

A Numerical Model for Dynamic Wave Rotor Analysis
2. REPOAT DATE
July 1995

\section{REPORT TYPE AND DATES COVERED}

Technical Memorandum

\section{FUNDING NUMBERS}

WU-505-62-50

6. AUTHOR(S)

D.E. Paxson

B. PERForming ORGANIZATION REPORT NUMBER

E-9776

National Aeronautics and Space Administration

Lewis Research Center

Cleveland, Ohio 44135-3191

10. SPONSORINGMONITORING AGENCY REPOFT NUMBER

National Aeronautics and Space Administration

Washington, D.C. 20546-0001

NASA TM-106997

AIAA-95-2800

\section{SUPPLEMENTARY NOTES}

Prepared for the 31st Joint Propulsion Conference and Exhibit cosponsored by AIAA, ASME, SAE, and ASEE, San

Diego, California, July 10-12, 1995. Responsible person, D.E. Paxson, organization code 2560, (216) $433-8334$.

12a. DISTAIBUTIONAVAILABILTTY STATEMENT

12b. DISTRIBUTION CODE

Unclassified - Unlimited

Subject Category 07

This publication is available from the NASA Center for Aerospace Information, (301) 621-0390.

13. ABSTRACT (Maximum 200 words)

A numerical model has been developed which can predict the dynamic (and steady state) performance of a wave rotor, given the geometry and time dependent boundary conditions. The one-dimensional, perfect gas, CFD based code tracks the gasdynamics in each of the wave rotor passages as they rotate past the various ducts. The model can operate both on and off-design, allowing dynamic behavior to be studied throughout the operating range of the wave rotor. The model accounts for several major loss mechanisms including finite passage opening time, fluid friction, heat transfer to and from the passage walls, and leakage to and from the passage ends. In addition it can calculate the amount of work transferred to or from the fluid when the flow in the ducts is not aligned with the passages such as occurs in off-design operation. Since it is one-dimensional, the model runs reasonably fast on a typical workstation. This paper will describe the model and present the results of some transient calculations for a conceptual four port wave rotor designed as a topping cycle for a small gas turbine engine.

14. SUBJECT TERMS

Wave rotor; Computational fluid dynamics; Transient; Aeropropulsion

13

$\mathrm{AO3}$

\begin{tabular}{|c|c|}
\hline $\begin{array}{c}\text { 17. SECURITY CLASSIFICATION } \\
\text { OF REPORT } \\
\text { Unclassified }\end{array}$ & $\begin{array}{c}\text { 18. SECURITY CLASSIFICATION } \\
\text { OF THIS PAGE } \\
\text { Unclassified }\end{array}$ \\
\hline
\end{tabular}

19. SECURIY CLASSIFICATION OF ABSTRACT Unclassified 